\title{
Functional tongue reconstruction with the anterolateral thigh flap
}

\author{
Xue Wang ${ }^{1}$, Guangqi Yan', Guirong Zhang ${ }^{2}$, Jiqiang Li ${ }^{2}$, Jihui Liu ${ }^{2}$ and Yang Zhang ${ }^{\text {** }}$
}

\begin{abstract}
Background: A retrospective study was conducted to evaluate the advantages of anterolateral thigh (ALT) flap in tongue reconstruction.

Method: From September 2008 to February 2012, patients receiving ALT flap tongue reconstruction were included in the study. Patients undergoing ALT flap were compared with those undergoing similar surgery with radial forearm flap (RFF). The medical records of the included patients were reviewed, and a questionnaire was used to assess acceptability of the surgery.

Results: All flaps (both ALT and RFF) were successful In the ALT group, most patients were satisfied with the appearance of the reconstructed tongue and the intelligibility of their speech, and there were fewer complications with this technique compared with the RFF.

Conclusion: The ALT flap is an ideal method for tongue reconstruction. The thickness and volume of the ALT flap can be adjusted based on the individual extent of the defect, and it can not only provide bulk but also ensure mobility, and it has other advantages also, including a long pedicle and low donor site morbidity.
\end{abstract}

Keywords: Anterolateral thigh flap, Functional outcome, Tongue reconstruction, Microsurgery

\section{Background}

Tongue carcinomas are the most common oral carcinomas [1]. The current treatment strategies for tongue carcinomas are mainly surgery-based comprehensive therapies. There are many methods suitable for defects after ablative surgery or for small or mid-sized defects, including primary closure or local flaps. For large defects, however, reconstruction remains one of the most challenging problems. The tongue plays a key role in speech and deglutition, therefore the ideal reconstructive method should provide not only satisfactory structural cosmesis, but also good restoration of function.

The anterolateral thigh (ALT) free flap was first described by Song et al. in 1984 [2]. Wei et al. [3] reported that the failure rate of the ALT free flap was less than $2 \%$, and they concluded that the ALT flap could replace most other flaps for soft tissue, because of the availability of a long pedicle with a suitable vessel diameter, versatility in design, and low donor site morbidity. The

\footnotetext{
* Correspondence: wang666666xue@163.com

${ }^{1}$ School of Stomatology, China Medical University, No. 117, Nanjing North

Street, Heping District, Shenyang, Liaoning 110002, PR China

Full list of author information is available at the end of the article
}

ALT flap has since become a standard technique for reconstructive microsurgery, with many reports about its application for reconstruction of the head and neck, upper and lower extremities, and the trunk and breast [4-22], but few reports exist on its use in tongue reconstruction.

Here, we present our experience with the ALT flap for defects of the tongue and floor of the mouth, highlighting the reasons for its versatility and benefits, and presenting analyses of the functional results.

\section{Methods \\ Patients}

During the period September 2008 to February 2012, 53 patients underwent simultaneous tumor resection and free ALT flap reconstruction of tongue and mouth floor defects at the Oral-maxillofacial Head and Neck Tumor Center (China Medical University, Shenyang, China). To evaluate the advantages of ALT flap more clearly, we made a comparison between the group receiving ALT and a similar group in which all patients (from September 2008 to February 2012) received radial forearm flap (RFF) reconstruction for defects in the tongue and mouth floor. For each patient,

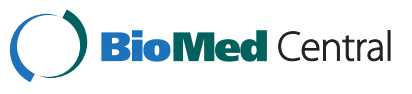


the choice of flap type was based on the surgeon's experience, defect size, and the patient's characteristics.

\section{Surgery}

One surgical team resected the tumor, and neck dissection was carried out according to the status of each case. A a plastic surgery team focused on harvesting the tissue for the ALT free flap commensurate with the size of the defect. Perforator detection, dissection, and planning of the ALT flaps were performed as described elsewhere [4,6,7]. First, a line was drawn from the anterior superior iliac spine to the superolateral border of the patella, then the midpoint of this line was determined, because the dominant perforators supplying the flap are located within a circle of $3 \mathrm{~cm}$ radius from this point. An incision was made in the sub-fascial plane to identify the location of the perforators and isolate them. At least one of the largest perforators was identified, others can be divided. If necessary, in order tot enhance the reliability of three-dimensional reconstruction, the inclusion of more than one perforator was used, as this improved the safety of the procedure. Once the perforator was confirmed, the skin paddle position could be adjusted appropriately. Depending on the type of ALT free flap needed, the volume and thickness of the could be tailored to the individual extent of the defect.

\section{Questionnaire}

Internal review board authorization was approved for a retrospective chart review. All the medical records were reviewed. At least 6 months after surgery, a functional analysis was conducted. Speech was analyzed postoperatively according to the method described by Song et al. [3]. We designed a questionnaire to investigate the differences between the ALT and RFF groups.

\section{Statistical analysis}

SPSS 13.0 was used to analyze the data, and $P<0.05$ was considered statistically significant.

\section{Results}

In the study, 53 patients underwent reconstruction with the ALT flap. The male-female ratio was $4: 1$, and the average age was 56.5 years (range: 34 to 70 ). According to the UICC 2002 TMN staging classification, $10 \mathrm{pa}$ tients were classified as T2, 27 patients as T3, and the remaining $16 \mathrm{t}$ as $\mathrm{T} 4$ (Table 1 ).

This patients were compared with 44 patients who underwent reconstruction with RFF. In this group, the average age was 58.0 years. There were 14 patients staged as T2, 20 patients as T3, and 10 patients as T4.

In both groups, there was 100\% survival of all flaps. Ten patients in the ALT group and eight patients in the RFF group received post-operative radiotherapy.
Table 1 Details of the included patients

\begin{tabular}{|c|c|c|c|}
\hline Characteristic & $\begin{array}{l}\text { ALT flap } \\
(n=53)\end{array}$ & $\begin{array}{l}\text { RFF flap } \\
(n=44)\end{array}$ & $P$ value \\
\hline Age, years; mean (range) & 56.5 (34 to 70$)$ & 58.0 (32 to 73$)$ & 0.875 \\
\hline Male: female ratio, $\mathrm{n}$ & $42: 11$ & $34: 10$ & 0.814 \\
\hline \multicolumn{4}{|l|}{ Tumor stage } \\
\hline $\mathrm{T} 2$ & 10 & 14 & 0.320 \\
\hline T3 & 27 & 20 & \\
\hline T4 & 16 & 10 & \\
\hline Flap size, $\mathrm{cm}^{2}$ & 48.5 & 50.0 & 0.786 \\
\hline Complications, n & 3 & 2 & 1.000 \\
\hline Total survival rate, $\%$ & 100 & 100 & 1.000 \\
\hline Post-operative radiotherapy, $\mathrm{n}$ & 10 & 8 & 0.931 \\
\hline
\end{tabular}

Abbreviations: ALT, anterolateral thigh; RFF, radial forearm flap.

During surgery, the type of perforator was identified as the musculocutaneous perforator in 46 patients. In most cases, there was only one perforator used. The flap sizes ranged from $24 \mathrm{~cm}^{2}(3 \times 8 \mathrm{~cm})$ to $84 \mathrm{~cm}^{2}(7 \times 12 \mathrm{~cm})$, with the average flap measuring $48.5 \mathrm{~cm}^{2}(5.1 \times 9.5 \mathrm{~cm})$. Eighteen flaps were harvested as myocutaneous flaps, while the rest were fasciocutaneous flaps. In all flaps, the anatomized vascular vessels were one artery and one vein. There were complications in three flaps within 36 hours after surgeon. A hematoma developed in two flaps; we immediately conducted an exploratory procedure, and found they were caused by non-ligation of venules, which was then corrected. The remaining flap developed vein obstruction; we confirmed that this was due to insufficient anastomosis and re-performed anastomosis again. Despite these problems, all flaps survived.

Speech evaluation showed that 12 patients had good speech intelligibility, 30 patients had acceptable intelligibility, and 11 patients had poor intelligibility.

The results of the questionnaire are shown in Table 2. In general, there were higher levels of acceptability for the ALT flap compared with the RFF, and this was statistically significant for the appearance and level of paresthesia of the donor site.

\section{Discussion}

Use of the ALT flap is now widespread for head and neck reconstruction. In the majority of cases, the ALT flap is based on the descending branch of the lateral femoral circumflex artery. This artery gives off either musculocutaneous or septocutaneous perforator vessels. A number of authors have reported that the most common perforators were musculocutaneous [4-11], and our study findings (86.8\% musculocutaneous) are consistent with this.

In our study, we mainly harvested myocutaneous and fasciocutaneous flaps, because we consider that primary 
Table 2 Outcomes of questionnaire

\begin{tabular}{|c|c|c|c|c|c|}
\hline \multirow{2}{*}{\multicolumn{2}{|c|}{ Question }} & \multirow[t]{2}{*}{ Answer } & \multicolumn{2}{|c|}{ Group } & \multirow{2}{*}{$\begin{array}{l}P \\
\text { value }\end{array}$} \\
\hline & & & ALT & RFF & \\
\hline \multirow[t]{2}{*}{1} & \multirow{2}{*}{$\begin{array}{l}\text { Are you satisfied with the shape of } \\
\text { your reconstructed tongue? }\end{array}$} & Yes & 48 & 40 & 1.000 \\
\hline & & No & 5 & 4 & \\
\hline \multirow[t]{2}{*}{2} & \multirow{2}{*}{$\begin{array}{l}\text { Are you satisfied with the } \\
\text { appearance of the donor site? }\end{array}$} & Yes & 53 & 6 & $<0.001$ \\
\hline & & No & 0 & 38 & \\
\hline \multirow{2}{*}{\multicolumn{2}{|c|}{$\begin{array}{l}3 \text { Is there paresthesia in the donor } \\
\text { site? }\end{array}$}} & Yes & 3 & 39 & $<0.001$ \\
\hline & & No & 50 & 5 & \\
\hline \multirow{2}{*}{\multicolumn{2}{|c|}{$\begin{array}{l}4 \text { Is there weakness in your operated } \\
\text { limb? }\end{array}$}} & Yes & 2 & 4 & 0.406 \\
\hline & & No & 51 & 40 & \\
\hline
\end{tabular}

Abbreviations: ALT, anterolateral thigh; RFF, radial forearm flap.

thinning of the ALT flap may increase the risk of failure, as suggested by Sharabi et al. [7]. The choice of myocutaneous or fasciocutaneous flap for each patient was based on the size of the defect and the experience of the surgeons. We found that dissection time was somewhat decreased with the ALT myocutaneous flap. We found that harvesting muscle had some important advantages. First, it obliterated dead spaces in the sub-mandible and prevented infections and fistula; in our study, 18 patients with myocutaneous flap had no complications caused by dead space. Second, the volume of the reconstructed tongue is an important factor for swallowing. As the muscular component of the ALT myocutaneous flap could provide adequate bulk, it had a a positive effect in permitting sufficient contact between tongue and palate, thus benefitting the deglutition procedure.

The donor site of the ALT flaps could be repaired by primarily closure, and complications were less frequent than with the RFF (Table 2), suggesting superiority of the ALT flap.

Some modifications of the ALT flap technique are possible. First, the ALT flap can be harvested as a sensation flap through the adjacent anterior branch of the femoral cutaneous nerves. In our previous study [11], we used a sensation ALT flap to reconstruct the defect after parotid malignant tumor in one case, and achieved a satisfactory result. Second, the tensor fascia latae of the ALT flap can enhance its specific properties. In a study conducted by Kuo et al. [12], 15 patients with extensive composite defects of the cheek and lip received ALT flaps together with the vascularized fascia and most of them achieved satisfactory outcomes. Third, the ALT flap can be raised as a chimeric flap for three-dimensional reconstruction. In our previous report, we described the reliability of chimeric ALT flaps for soft tissue defects in the head and neck [11].

The main goal of tongue reconstruction is restoration of deglutition and speech. Previous studies [18-20,23] showed that speech intelligibility is closely linked with the mobility of the remaining normal tongue, and that swallowing capacity had a strong relationship with the volume of the reconstructed tongue. Thus, the ideal method for tongue reconstruction should provide both bulk and mobility, and the ALT flap complies with both of these conditions. In our study, most patients achieved satisfactory speech function. However, our experience suggests that this good result can be partially explained by other factors: 1) few patients received post-operative radiotherapy; 2) we focused on achieving a closer resemblance to the three-dimensional shape of the actual tongue [24], and in fact, $90.6 \%$ of the cases were satisfied with their reconstructed tongue; 3 ) we usually harvested an ALT flap that was approximately 20 to $30 \%$ larger than the actual defect to allow for tissue atrophy; and 4) we tried to preserve as much of the remaining tongue as possible in every case.

\section{Conclusions}

In summary, we assessed the use of the ALT flap compared with the RFF for defects of the tongue and floor of the mouth. We found that the ALT flap can not only provide bulk but also ensure mobility, along with several other advantages, including availability of a long pedicle and the low donor site morbidity. The thickness and volume of the ALT flap can be adjusted based on the individual extent of the defect. We consider that these benefits make the ALT flap an ideal method for tongue reconstruction. In patients lacking suitable perforators for an ALT flap, an anteromedial thigh flap is a good alternative method [25]. Based on our experience, we recommend that ALT should be the first choice for defects in the tongue and the floor of the mouth.

\section{Consent}

Written informed consent was obtained from the patient for the publication of this report and any accompanying images.

\section{Competing interests}

The authors declare that they have no competing interests.

\section{Authors' contributions}

XW has made contribution to conception, design, acquisition of information and write this paper; GY, RZ, $J$, $J$ have made contribution to analysis and interpretation of data; $Y Z$ have made contribution to help draft the manuscript and revise the paper. All authors read and approved the final manuscript.

\section{Author details}

${ }^{1}$ School of Stomatology, China Medical University, No. 117, Nanjing North Street, Heping District, Shenyang, Liaoning 110002, PR China. ${ }^{2}$ Stomatology Hospital of Shenyang, No. 138, Zhongshan Road, Heping District, Shenyang, Liaoning 110002, PR China.

Received: 15 May 2013 Accepted: 9 November 2013

Published: 25 November 2013 


\section{References}

1. Hirose J: General rules for Clinical and Pathological Studies on Head and Neck Cancer. 2nd edition. Tokyo: Kinbara: Japan Society for Head Neck Cancer; 1991:101.

2. Song $Y G$, Chen $G Z$, Song $Y L$ : The free thigh flap: a new free flap concept based on the septocutaneous artery. Br J Plast Surg 1984, 37:149-159.

3. Wei FC, Jain V, Celik N, Chen HC, Chuang DC, Lin CH: Have we found an ideal soft-tissue flap? An experience with 672 anterolateral thigh flaps. Plast Reconstr Surg 2002, 109:2219-2226.

4. Nasajpour H, Steele MH: Anterolateral thigh free flap for "head-to-toe" reconstruction. Ann Plast Surg 2011, 66:530-533.

5. Lee JC, Hugo SH, Christy MR, Wise MW, Rodriguez ED: Anterolateral thigh flap for trauma reconstruction. Ann Plast Surg 2011, 64:164-168.

6. Chen HC, Tang YB: Anterolateral thigh flap: an ideal soft tissue flap. Clin Plast Surg 2003, 30:383-401.

7. Sharabi SE, Hatef DA, Koshy JC, Jain A, Cole PD, Hollier LH Jr: Is primary thinning of the anterolateral thigh flap recommended? Ann Plast Surg 2010, 65:555-559.

8. Ichinose A, Terashi H, Nakahara M, et al: Do multiple venous anastomoses reduce risk of thrombosis in free-flap transfer? Efficacy of dual anastomoses of separate venous systems. Ann Plast Surg 2004, 52:61-63.

9. Boca R, Kuo YR, Hsieh $\mathrm{CH}$, Huang EY, Jeng SF: A reliable parameter for primary closure of free anterolateral thigh donor site. Plast Reconstr Surg 2010, 126:1558.

10. di Candia MD, Lie K, Kumiponjera D, Simcock J, Cormack GC, Malata CM: Versatility of the anterolateral thigh free flap: the four seasons flap. Eplasty 2012, 12:e21.

11. Xu ZF, Dai W, Zhang EJ, et al: Perforator-based chimeric anterolateral thigh flap for head and neck reconstruction after en bloc resection. Shanghai Kou Qiang Yi Xue 2012, 21:107-112.

12. Kuo YR, Jeng SF, Wei FC, Su CY, Chien CY: Functional reconstruction of complex lip and cheek defect with free composite anterolateral thigh flap and vascularized fascia. Head Neck 2008, 30:1001-1006.

13. Sun GW, Lu MX, Tang EY, Yang X, Wen J, Wang J: Clinical application of free anterolateral thigh flap in the reconstruction of intraoral defects. Oral Surg Oral Med Oral Pathol Oral Radiol Endod 2011, 112:34-41.

14. Lee YC, Chiu HY, Shieh SJ: The clinical application of the anterolateral thigh flap. Plast Surg Int 2011, 2011:127353.

15. Yamaguchi K, Kimata Y, Onoda S, Mizukawa N, Onoda T: Quantitative analysis of free flap volume changes in head and neck reconstruction. Head Neck 2011, 34:1403-1407.

16. Park CW, Miles BA: The expanding role of the anterolateral thigh free flap in head and neck reconstruction. Curr Opin Otolaryngol Head Neck Surg 2011, 19:263-268.

17. Bianchi B, Ferri A, Ferrari S, Copelli C, Boni P, Ferri T, Sesenna E: The free anterolateral thigh musculocutaneous flap for head and neck reconstruction: one surgeon's experience in 92 cases. Microsurgery 2012, 32:87-95.

18. Engel H, Huang JJ, Lin CY, Lam W, Kao HK, Gazyakan E, Cheng MH: A strategic approach for tongue reconstruction to achieve predictable and improved functional and aesthetic outcomes. Plast Reconstr Surg 1967, 2010:126.

19. Kimata Y, Sakuraba M, Hishinuma S, et al: Analysis of the relations between the shape of the reconstructed tongue and postoperative functions after subtotal or total glossectomy. Laryngoscope 2003, 113:905-909.

20. Yun IS, Lee DW, Lee WJ, Lew DH, Choi EC, Rah DK: Correlation of neotongue volume changes with functional outcomes after long-term follow-up of total glossectomy. J Craniofac Surg 2010, 21:111-116.

21. Bokhari WA, Wang SJ: Tongue reconstruction: recent advances. Curr Opin Otolaryngol Head Neck Surg 2007, 15:202-207.

22. Chana JS, Wei FC: A review of the advantages of the anterolateral thigh flap in head and neck reconstruction. Br J Plast Surg 2004, 57:603-609.

23. Revenaugh PC, Knott PD, Alam DS, Kmiecik J, Fritz MA: Voice outcomes following reconstruction of laryngopharyngectomy defects using the radial forearm free flap and the anterolateral thigh flap. Laryngoscope 2013 [Epub ahead of print].
24. Longo B, Pagnoni M, Ferri G, Morrello R, Santanelli F: The mushroom-shaped anterolateral thigh perforator flap for subtotal tongue reconstruction. Plast Reconstr Surg 2013, 132:656-665.

25. Xu ZF, Sun CF, Duan WY, et al: Clinical anatomical study and evaluation of the use of the free anteromedial thigh perforator flaps in reconstructions of the head and neck. Br J Oral Maxillofac Surg 2011. Epub ahead of print

doi:10.1186/1477-7819-11-303

Cite this article as: Wang et al:: Functional tongue reconstruction with the anterolateral thigh flap. World Journal of Surgical Oncology 2013 11:303.

\section{Submit your next manuscript to BioMed Central and take full advantage of:}

- Convenient online submission

- Thorough peer review

- No space constraints or color figure charges

- Immediate publication on acceptance

- Inclusion in PubMed, CAS, Scopus and Google Scholar

- Research which is freely available for redistribution

Submit your manuscript at www.biomedcentral.com/submit
( Biomed Central 